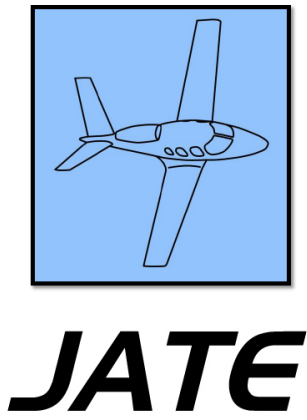

Journal of Aviation Technology and Engineering 5:1 (2015) 2-6

\title{
Synthesis of Unmanned Aircraft Systems Safety Reports
}

\author{
Robert Joslin
}

Embry-Riddle Aeronautical University

\begin{abstract}
The proliferation and extension of unmanned aircraft systems from military to civil and public use applications has rapidly outpaced the safety analysis that is normally associated with the introduction of a new and novel aircraft. Insights into the types of anomalous events associated with accidents and incidents involving civil and public use unmanned aircraft systems operating in the National Airspace System were derived from an information synthesis of archival, publically available reports from the Aviation Safety Information and Analysis Sharing system. The vast majority of anomalous events were related to equipment failures, primarily lost link, distantly followed by a variety of non-equipment-related events involving pilot/operator errors, such as near-mid-air collisions, altitude deviations, airspace violations, and procedural deviations. The identification of types of anomalous events associated with safety reports provided insights for consideration when developing and implementing mitigation strategies for the design, training, and operation of unmanned aircraft systems.
\end{abstract}

Keywords: unmanned aircraft systems, safety reports, accidents and incidents, Aviation Safety Information Analysis and Sharing

\section{Introduction}

The proliferation of civil and public use unmanned aircraft systems (UAS) throughout the United States and the rest of the world has outpaced the safety analysis that is normally associated with the introduction of a new and novel aircraft with unique operating characteristics and capabilities. In accordance with 49 U.S.C. §40102(a)(41) and 14CFR §1.1, public use aircraft are those performing noncommercial governmental functions such as national defense, intelligence missions, firefighting, search-and-rescue, law enforcement, aeronautical research, or biological or geological resource management.

\section{About the Authors}

Robert Joslin currently serves as the FAA's chief scientific and technical advisor for flight deck technology as well as an adjunct assistant professor with Embry-Riddle Aeronautical University-Worldwide. He previously served as a colonel in the US Marine Corps as a military test pilot, and remains an active test pilot with the FAA. He is a fellow with the Royal Aeronautical Society, associate fellow with the Society of Experimental Test Pilots, full member of the International Society of Air Safety Investigators, and a full member of the Human Factors \& Ergonomics Society. His special credentials as related to this technical paper also include currently serving on the Aviation Rulemaking Committee for Unmanned Aircraft Systems, RTCA Special Committee-228 and ASTM F-38 Committee responsible for developing UAS/sUAS certification standards. Joslin holds FAA ratings and military qualifications in aircraft ranging from large transports and business jets, to general aviation airplanes, seaplanes, helicopters, and powered lift aircraft, and is also a qualified RQ-12 WASP and RQ-20 Puma Pilot/operator and has completed the MQ-9 Predator pilot familiarization course. Correspondence concerning this article should be sent to joslinr@erau.edu. 
Unmanned aircraft systems were considered to encompass all related definitions, including but not limited to unmanned aerial vehicles, unmanned aviation systems, small unmanned aircraft systems, remotely pilot aircraft systems, remotely operated aircraft, and remotely piloted vehicles, but not model aircraft used for hobby and recreation, per Federal Register, 14 CFR Part 91 [Docket No. FAA-20140396] Interpretation of the Special Rule for Model Aircraft. Unmanned aircraft systems are currently operated under a Certificate of Authorization (COA), which include explicit data reporting provisions for accidents and incidents (FAA, 2014a, 2014b). Pending updates to the current Federal Aviation Regulations (FAR) that can accommodate Unmanned Aircraft Systems, Section 333 of the FAA Modernization and Reform Act of 2012 added provisions for exemptions and waivers to the FAR through COA's that consider size, weight, speed, operational capability, proximity to airports and populated areas, and operation within visual line of sight that do not create a hazard to users of the national airspace system or the public or pose a threat to national security.

Previous studies of UAS accidents and incidents (Merlin, 2013; Manning, Rash, LeDuc, Noback, \& McKeon, 2004; Tvaryanas \& Thompson, 2008; Williams, 2004) relied primarily on U.S. military data from hostile and nonhostile operations worldwide. However, the maturation of civil and public use UAS operations has generated accident and incident data from hundreds of events in the National Airspace System (NAS), which demands an analysis to identify the types of anomalous events so that they can be considered when developing and implementing mitigation strategies for the design, training, and operation of unmanned aircraft systems. A similar study on civil and public use UAS accidents and incidents was conducted by Joslin (2015); however, that study only considered reports from the Federal Aviation Administration preliminary reports of Unmanned Aircraft Systems Accidents and Incidents (FAA UAS A\&I) database. This study expanded on Joslin's (2015) study by including reports from the National Transportation Safety Board (NTSB), Near Mid-Air Collision System (NMACS), and voluntary reports submitted through the Aviation Safety Reporting System (ASRS).

\section{Data Source}

The source of information for this study was 327 reports that were publically available in the Aviation Safety Information Analysis and Sharing (ASIAS) database administered by the FAA. Although all of the data were extracted from ASIAS in October 2014, the date range was based on the latest periodic update cycle for each individual dataset, which varied for each source. ASIAS provided access to multiple data sources, four of which had reports of UAS accidents and incidents (Table 1). These data included 274 reports from the Federal Aviation Administration Preliminary Reports of Accidents and Incidents database (FAA UAS A\&I), which became available in May 2014 and was populated with civil and public use accidents and incidents in the NAS since April 2010.

Initially, the FAA UAS A\&I database was populated with data starting in October 2009 and included sensitive events involving Department of Homeland Security (DHS) public use unmanned aircraft systems. Those data were subsequently removed from the online database; however, they were available and included in redacted form for this study. There were 24 voluntary reports submitted through the Aviation Safety Reporting System that involved unmanned aircraft. The ASRS is administered by the National Aeronautics and Space Administration (NASA) through a memorandum of agreement with the FAA and was designed to encourage voluntary self-reporting by pilots of anomalous aviation events, which were then compiled using a unique ASRS taxonomy (FAA, 2011; NASA, 2012).

Eleven voluntary reports involving UAS were submitted through the Near Mid-Air Collision System. An NMAC is defined as an incident associated with the operation of an aircraft in which a possibility of collision occurs as a result of proximity of less than 500 feet to another aircraft, or a report is received from a pilot or a flight crewmember stating that a collision hazard existed between two or more aircraft. The NMACS business rules stated that any studies based on NMAC reports should consider that the data could be subjective and that the number of NMAC reports filed did not represent the total universe of such events.

Furthermore, the submission of an NMAC report can be influenced by a number of factors. Pilot experience and the operational airspace in which they operate can influence reporting. For example, pilots who routinely fly in heavily used airspace, and are used to flying relatively close to other aircraft, may be less likely to file a report than a pilot who usually flies in sparsely populated airspace. The accuracy of the reporting individual's perception of an NMAC can vary considerably among the flight crewmember population. Factors include experience, visibility conditions, the proximity of aircraft involved, relative angle of approach, size of the aircraft involved, and the trauma experienced by the pilot or flight crew.

The National Transportation Safety Board (NTSB) accident and incident database had archived 18 events involving UAS, recorded in compliance with the reporting requirements under 49 CFR Part 830 §830.5. An unmanned aircraft accident is defined as an occurrence associated with the operation of any public or civil unmanned aircraft system that takes place between the time that the system is activated with the purpose of flight and the time that the system is deactivated at the conclusion of its mission, in which: (1) any person suffers death or serious injury; or (2) the aircraft has a maximum gross takeoff weight of 300 pounds or greater and sustains substantial damage. 
Table 1

ASIAS sources with UAS accidents and incidents reports as of October 2014.

\begin{tabular}{|c|c|c|}
\hline Database & Date Range & Number of UAS Reports \\
\hline FAA Accident and Incident Data System (AIDS) & 1978-2014 (30 Sept) & 0 \\
\hline FAA Runway Safety Office-Runway Incursions (RWS) & 2001-2014 (1 Oct) & 0 \\
\hline NTSB Aviation Accident and Incident Data System & 1982-2014 (29 Sep) & $18^{*}$ \\
\hline FAA Near Mid-Air Collision (NMAC) & $1987-2014$ (12 Oct) & 11 \\
\hline Aviation Safety Reporting System (ASRS) & 1988-2014 (30 Sep) & $24 * *$ \\
\hline $\begin{array}{l}\text { FAA Preliminary Reports of Unmanned Aircraft System } \\
\text { Accidents and Incidents }\end{array}$ & 2009 (31 Oct)-2014 (21 Aug) & 274 \\
\hline
\end{tabular}

*Five of the NTSB reports were also recorded in the FAA UAS A\&I.

** One of the ASRS reports was also recorded in the FAA UAS A\&I

There were no UAS-related reports in the FAA Runway Safety Office-Runway Incursion System (RWS). This is defined as any occurrence at an aerodrome involving the incorrect presence of an aircraft, vehicle, or person on the protected area of a surface designated for the landing and takeoff of aircraft. Additionally, there were no UAS-related reports in the FAA Accident and Incident Database (AIDS). The FAA Accident and Incident Data System database contains data for events that do not meet the aircraft damage or personal injury thresholds contained in the NTSB's definition of an accident.

\section{Methodology}

This study informed the ASIAS database by identifying specific types of UAS anomalous events through an innovative application of the taxonomy from the Aviation Safety Reporting System. Each database in ASIAS utilized a unique taxonomy for types of anomalous events, such as the FAA UAS A\&I database that distinguished five types (and 40 subtypes) of events (Table 2). However, the ASRS provided the most comprehensive taxonomy by distinguishing 15 types (and 53 sub-types) of events, thereby providing the most refinement as to the specific nature of the events (Table 3 ).

Simple quantitative frequency counts of each type of anomalous event were derived by the author through text mining of the ASIAS report descriptions using the ASRS taxonomy. Most event types had various subtypes. For example, an Inflight Encounter event had subtype events for Near Mid-Air Collision, Controlled Flight Into Terrain, Loss of Control, Weather/Turbulence, and Visual Flight Rules in Instrument Meteorological Conditions. Only those event types and subtypes germane to this study were presented in the findings.

The ASRS taxonomy was developed for manned aircraft, which, in some cases, did not directly apply to UAS operations, such as a Flight Deck/Cabin event. Hence, anomalous events involving ground infrastructure supporting a UAS control station (e.g., utilities) were considered Flight Deck/Cabin events, and noncompliance with a Certificate of Authorization (the authority, issued by the FAA Air Traffic Organization, needed to operate a UAS in the National Airspace System as a public aircraft) or pilot/ operator checklist/procedure was considered a Procedural Deviation type anomalous event.

There was no distinction made between sUAS and UAS, hence the term UAS applied to both. Small unmanned aircraft systems, or sUAS, are unmanned aircraft weighing less than 55 pounds. There also was no distinction made between types of control stations (e.g., ground, sea, air, motor vehicle, hand-controller).

Lost link is an interruption or loss of the command and control link between the control station and aircraft, which can be the uplink that transmits command instructions to the aircraft and/or the downlink that transmits navigational, surveillance, separations assurance/see-and-avoid, and status of the aircraft. It is also an interruption or loss of the

Table 2

FAA unmanned aircraft accident and incident report form-taxonomy.

\begin{tabular}{|c|c|}
\hline Event Type & Event Subtype \\
\hline $\begin{array}{l}\text { Deviations from ATC } \\
\text { clearance and/or Letters } \\
\text { of Agreement/Procedures }\end{array}$ & $\begin{array}{l}\text { Altitude Increase/decrease* } \\
\text { Assigned Routing Deviation* }\end{array}$ \\
\hline Lost Control Link Events & $\begin{array}{l}\text { Line-of-Sight or } \\
\quad \text { Beyond-Line-of-Sight } \\
\mathrm{Ku} \text { Band, C-Band, etc. } \\
\text { Uplink, Downlink or Both }\end{array}$ \\
\hline $\begin{array}{l}\text { Unusual Equipment Malfunctions } \\
\text { (partial list of sub-types) }\end{array}$ & $\begin{array}{l}\text { Navigation System Failures } \\
\text { Aborted take-off or landing } \\
\text { due to system failure } \\
\text { Takeoff or landing } \\
\text { damage to airframe } \\
\text { Fires-aircraft or control station } \\
\text { Control station-infrastructure } \\
\text { failure }\end{array}$ \\
\hline Aircraft Collisions & $\begin{array}{l}\text { Other aircraft } \\
\text { Persons } \\
\text { Terrain/water } \\
\text { Wildlife } \\
\text { Other Objects }\end{array}$ \\
\hline $\begin{array}{l}\text { All other deviations from the } \\
\text { provisions contained in the } \\
\text { Letter of Authorization and } \\
\text { not encompassed previously } \\
\text { in the report }\end{array}$ & \\
\hline
\end{tabular}

*Include the magnitude of deviation 
Table 3

ASRS types of anomalous events.

\begin{tabular}{|c|c|c|c|c|}
\hline Equipment $^{\mathrm{a}}$ & Airspace Violation & ATC Issues & Flt Deck/ Cabin ${ }^{b}$ & Conflict \\
\hline $\begin{array}{l}\text { Altitude Deviation } \\
\text { Ground Incursion }\end{array}$ & $\begin{array}{l}\text { Speed Deviation } \\
\text { Ground Encounter }^{\mathrm{d}}\end{array}$ & $\begin{array}{l}\text { Track/Heading Deviation } \\
\text { Inflight Encounter }\end{array}$ & $\begin{array}{l}\text { Procedural Deviation }{ }^{c} \\
\text { Other }\end{array}$ & $\begin{array}{l}\text { Ground Excursion } \\
\text { Undetermined }\end{array}$ \\
\hline
\end{tabular}

Note. (a)-Equipment anomalies were identified as either related or unrelated to a command and control lost link or communications link.

Note. (b)-Flight Deck/Cabin anomalies were redefined as events involving ground infra-structure facilities supporting a UAS control station (e.g. utilities). Note. (c)-Procedural Deviation included non-compliance with a Flight Clearance or Published Material/Policy (e.g. Certificate of Authorization; Operator's Manual).

Note. (d)-Ground Encounter was either a Ground Strike or Object.

Note. (e)-Inflight Encounters were sub-typed as Controlled Flight Into Terrain (CFIT), Loss of Control (LOC), Weather/Turbulence, or Visual Flight Rules in Instrument Meteorological Conditions (VFR in IMC), Near-Mid-Air-Collisions (NMAC).

(Source: http://asrs.arc.nasa.gov).

communication uplink and/or downlink link between the control station and air-traffic control. Lost link can be caused by equipment failures or degradations, pilot error, or an interruption or anomaly in the uplink/downlink frequency spectrum, the latter of which is difficult to determine at the operator level. Hence, lost links of any duration were attributed to either an equipment type anomalous event or pilot error, with no distinction made between short duration lost links, whereby the operation was continued, and those where the lost link procedures were executed. Lost links were categorized as either command and control (C2) link, or communications link.

\section{Findings}

\section{Types of Anomalous Events}

The most prevalent types of anomalous events were equipment failures/degradation, which were involved in $231(73 \%)$ of the events, as depicted in Figure 1. Nearly

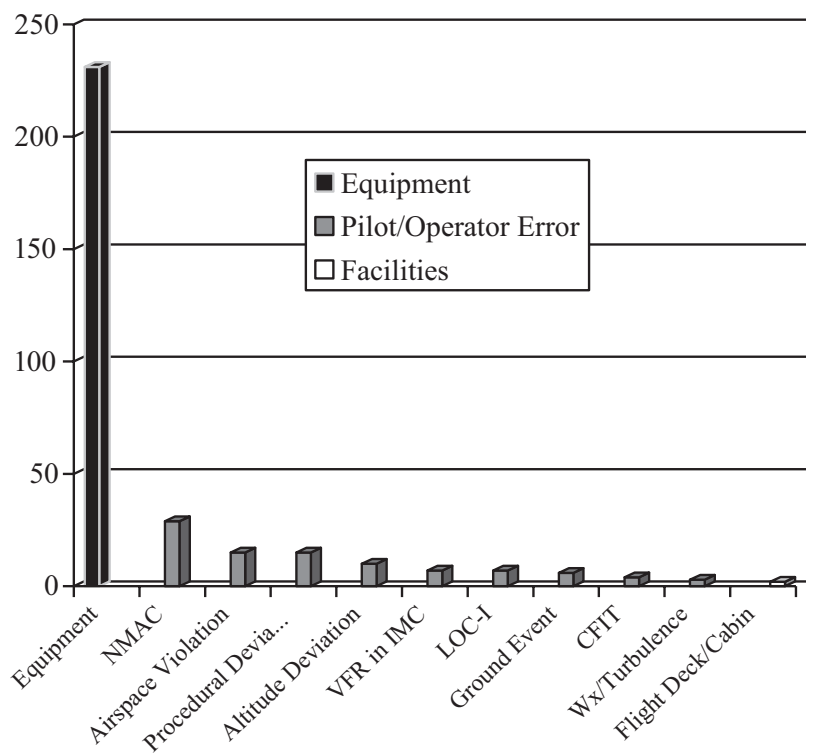

Figure 1. Types of anomalous events. Adapted from the Aviation Safety Information Analysis and Sharing (ASIAS) database using Aviation Safety Reporting System taxonomy. half (41\%) of the equipment events were related to C2 Lost Link (Figure 2). Four of the $\mathrm{C} 2$ lost links were due to pilot errors in the execution of link procedures, not equipment anomalies. There were no reports that cited an issue with the frequency spectrum as the cause of the lost link. In addition, there were 14 instances of lost communication link, where the UAS crew had to rely on telephonic communication with air-traffic control (ATC). The remaining equipment type anomalous events were related to failure/degradation of structural, avionics, electrical, or flight control components.

The top four anomalous events attributed to pilot/ operator error were Near Mid-Air Collisions, Airspace Violation, Altitude Deviation, and Procedural Deviation (Figure 1). The Inflight Encounter events consisted of the following subtypes: Near Mid-Air Collisions; Visual Flight Rules in Instrument Meteorological Conditions (VFR in IMC); Loss of Control (LOC), Weather/ Turbulence, and Controlled Flight into Terrain (CFIT). There were six ground events where the pilot either made a hard landing or impacted an object (e.g., runway edge lights). The two Flight Deck/Cabin-type events were related to facilities infrastructure, one involving a gas leak at a nearby support facility that resulted in an evacuation of the UAS control station, and the other from a commercial power loss due to a transformer failure, resulting in a temporary interruption of electrical power to the UAS control station.

The overall counts for types of anomalous events exceeded the number of reports, since some ASIAS reports involved multiple anomalous events (e.g., lost link due to equipment failure followed by the pilot's incorrect execution of the procedural checklist to recover the system). There were no events attributed directly to ATC issues. However, any occurrences would have been reported outside of ASIAS through internal FAA requirements such as the Air Traffic Mandatory Occurrence Report (MOR)FAA Form 7210-13, and hence were not available for this study. The MOR had provisions for reporting any expression of concern or inquiry by any external entity to a management official/controller-in-charge (CIC) or to ATC on the radio concerning the proximity or operation of 


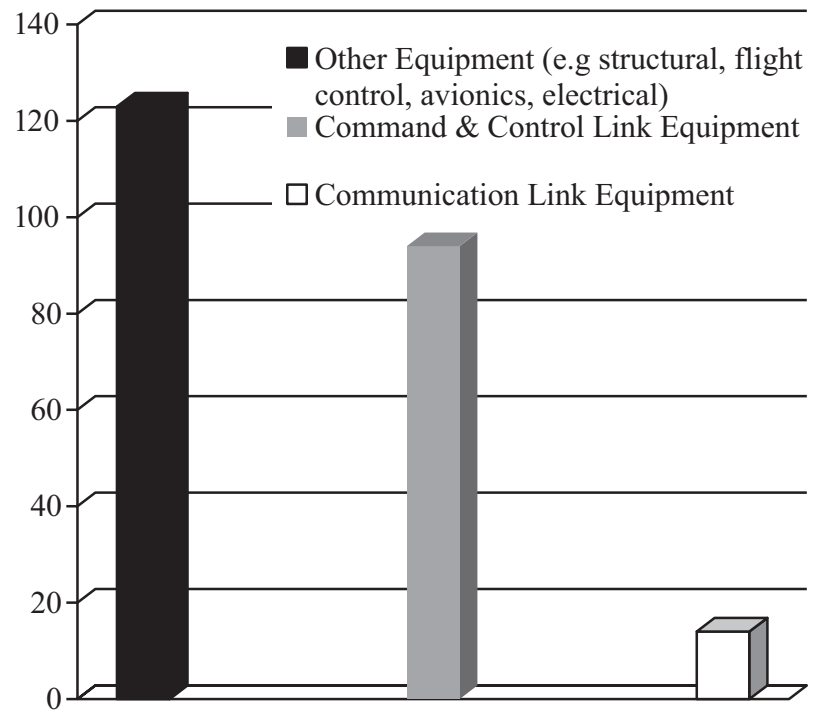

Figure 2. Equipment type anomalous events. Adapted from the Aviation Safety Information Analysis and Sharing (ASIAS) database.

an aircraft, either airborne or on the surface, including near mid-air collision notifications from a flight crew (FAA, 2012).

\section{Comparative Findings}

There were validity concerns with merging military data with civil and public use data, due to a variety of known dissimilar variables (e.g., operating environment, crew qualifications, equipage, and data frame). In addition, the military data included operations overseas, as well as the National Airspace System. However, in the absence of any recent analysis of substantial historical data for civil and public use UAS accidents and incidents, it was considered worthwhile to compare the results without examining the reasons for agreement or disagreement of the data.

The findings from this study were consistent with Merlin's (2013) research that attributed UAS mishaps primarily to hardware failure, insufficient training, and deficiencies, and Williams' (2004) assertion that electrical and mechanical reliability played as much or more of a role in UAS accidents as human error. An analysis by Manning et al. (2004) of 56 US Army UAS accidents for the period FY95-FY03 indicated that human error was present in approximately one-third $(32 \%)$ of the accidents, while this study indicated that $27 \%$ of the accidents and incidents examined could be attributed to pilot/operator error issues. All of the historical literature agreed with this study that equipment failures have been the most common type of anomalous event.

\section{Summary}

This study improved on the utility of the Aviation Safety Information and Analysis Sharing system databases to enhance aviation safety by identifying the most prevalent types of anomalous events associated with civil and public use unmanned aircraft system operations. The vast majority of the events were related to equipment failures, specifically command and control lost link, distantly followed by a variety of non-equipment related events involving pilot/ operator errors. Near Mid-Air Collision was the most frequent non-equipment error followed by airspace violation, altitude deviations, and procedural deviations. The study also revealed considerations unique to unmanned operations, which were anomalous events from degradation of facilities infrastructure that support UAS control stations, and the reliance on a telephonic system as a back-up communication link with air-traffic control. The practical application of the findings may be used when developing and implementing mitigation strategies for the design, training, and operation of civil and public use unmanned aircraft systems.

\section{References}

FAA. (2011). FAA Advisory Circular 00-63C Aviation Safety Reporting Program. Washington, DC: Federal Aviation Administration. Retrieved from http://faa.rgl.gov/

FAA. (2012). JO 7210632 Air Traffic Organization Occurrence Reporting. Washington, DC: Federal Aviation Administration.

FAA. (2013). FAA Advisory Circular 25.1302-1 Installed Systems and Equipment for Use by the Flightcrew. Washington, DC: Federal Aviation Administration. Retrieved from http://faa.rgl.gov/

FAA. (2014a). N JO 7210.873 Unmanned Aircraft Operations in the National Airspace System (NAS). Washington DC, Federal Aviation Administration.

FAA. (2014b). JO 7210.3Y Facility Operation and Administration. Washington, DC: Federal Aviation Administration.

Joslin, R. (2015). Insights into Unmanned Aircraft Systems Accidents and Incidents (2009-2014). Aviation, Aeronautics, Aerospace International Research Conference-2015, Phoenix, AZ. Washington, DC: Federal Aviation Administration.

Manning, S. D., Rash, C. E., LeDuc, P. A., Noback, R. K., \& McKeon, J. (2004). The role of human causal factors in US Army unmanned aerial vehicle accidents (No. USAARL-2004-11). Fort Rucker, AL: Army Aeromedical Research Lab.

Merlin, P. W. (2013). Crash Course: Lessons Learned from Accidents Involving Remotely Piloted and Autonomous Aircraft. Washington, DC: Government Printing Office.

NASA. (2012). Aviation Safety Reporting System [Online Database]. Washington, DC: National Aeronautics and Space Administration. Retrieved from http://asrs.arc.nasa.gov

Tvaryanas, A. P., \& Thompson, W. T. (2008). Recurrent error pathways in HFACS data: Analysis of 95 mishaps with remotely piloted aircraft. Aviation, Space, and Environmental Medicine, 79(5), 525-532. http:// dx.doi.org/10.3357/ASEM.2002.2008

Williams, K. W. (2004). A summary of unmanned aircraft accident/ incident data: Human factors implications (Publication No. DOT/ FAA/AM-04/24). Washington, DC: Federal Aviation Administration. 